\title{
The Speed Control of Constant Tension Motor of Marine Crane
}

\author{
Xinyang Chen ${ }^{1}$, Haiquan $\mathrm{Chen}^{1}$, Wenhua $\mathrm{Li}^{1}$, Shukai Shi ${ }^{2}$, Yuqing Sun ${ }^{1}$ \\ 1 Dalian Maritime University, Maritime Engineering College, 116026 Dalian, China \\ 2 Dalian Maritime University, College of Public Management \& the Humanities, 116026 Dalian, China
}

\begin{abstract}
This article describes the working principle of the marine beacon crane hanging disc mechanical anti-sway device, and establish mathematical model on the rope controlling hanging disc of mechanical anti-sway device; Through matlab simulation analysis, this article obtains the relation curve between the velocity of traction rope of hanging disc and output frequency of the crane motor, combining rotary crane scaled model, this article carries out anti-sway experiment for the rotary crane to examine the crane's anti-sway effects.
\end{abstract}

\section{Introduction}

Marine crane is a kind of special crane in the transport operations, it needs to control the load with swing in the process of work, so it is particularly important to ensure the position precision when the Marine crane is running and transportation efficiency, as well as the operation safety. In order to reduce the weight of shaking, this article describes the marine crane hanging disc mechanical anti-sway device, through resistance the hanging objects' simple pendulum motion is equivalent to reduce pendulum length. When the marine crane is working, the traction rope of hanging disc must be state of tension in order to show damping effect. To solve the swing of object on the Marine crane, there are two main types of solving method, one is Mechanical anti-sway, another is intelligent anti-sway. In the aspect of mechanical anti-sway, KIMIAGHALAM B established linear kinetic model for Maryland locks on the Marine crane, applying model predictive control and optimal control method to control of object swing $[1,2]$. In the aspect of intelligent anti-sway, the US Sandia National laboratory uses TSS POS/MV320 navigation system to measure ship orientation, use the combination of inertial measurement unit IMU, gyroscope and GPS to measure ship motion, and use position control strategy, all of which can better anti-sway of hanging objects $[3,4]$.

The article mainly to the establishment of the mathematical model of constant tension motor and calculate output frequency of the crane motor under different working condition.

\section{Setting up the mathematical model}

In this paper, a new type of rotary crane mechanical antisway device-hanging disc mechanical anti-sway device, the main purpose is decreasing rock caused by ship rocking conditions. Fig. 1 is crane disc anti-sway device model [5].

Crane mechanical rolling test system can be divided into three parts: the hoisting, derricking and slewing mechanism; the constant tension of electric drive system; hanging disc mechanical anti-sway device. Hanging disc mechanical anti-sway device includes: hanging disc, traction rope of hanging disc, anti-swing arm. The permanent magnetism synchronous servomotor of Siemens IFK7081 was adopted to be the constant tension motor, motor reducer's reduction ratio is 40:1. Hanging disc install above the hook, when the crane is working, traction rope of hanging disc must be synchronous movement with goods to keep the same degree of tension, at the same time, pressing the Anti-rolling button, the both sides of crane motor tighten at the same time to reduce the degree of swing.

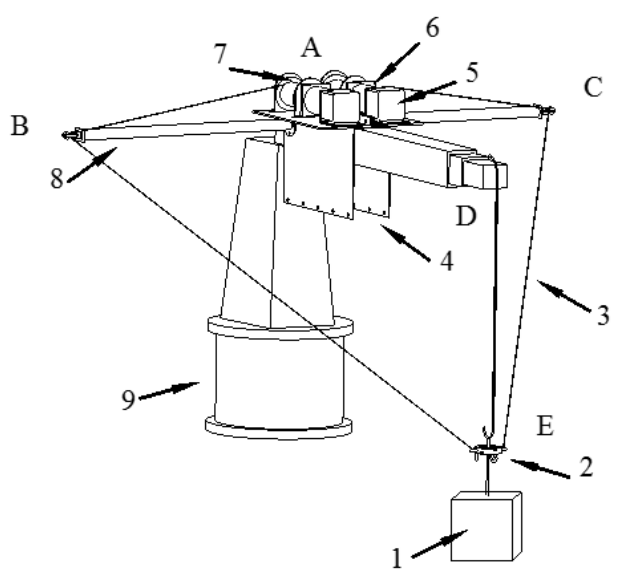

1 object 2 hanging disc 3 traction rope of hanging disc 4 base 5 motor 6 motor reducer 7 coiling block 8 antiswing arm 9 Marine crane

Figure 1. Crane disc anti-sway device model 


\subsection{Model calculation of anti-swing arm}

According to the shown in Fig. 1, anti-swing arm is very important in the anti-sway system to support the traction rope of hanging disc of normal work.According to the experiment, when the crane is working with $1000 \mathrm{~kg}$ load, the force of traction rope of hanging disc is $400 \mathrm{~N}$, antiswing arm can be simplified as a cantilever beam to determine the size, material is Q235 steel. For mathematical modelling, the assumption of ideal machine is used. Therefore, the effects of notches on stress distribution could be neglected in the governing equations [6-8]. The force is shown in Fig. 2:

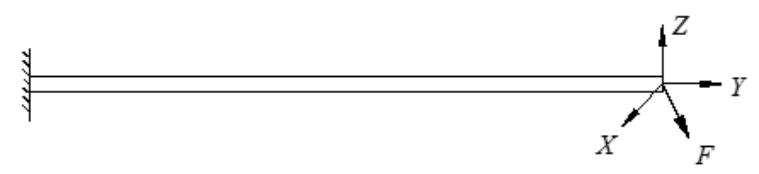

Figure 2. Force of anti-swing arm

The maximum bending moment and shear force of anti-swing arm:

$$
\begin{gathered}
M_{\text {max }}=F l \\
Q_{\text {max }}=F
\end{gathered}
$$

The maximum bending normal stress and maximum bending shear stress of anti-swing arm:

$$
\begin{gathered}
\sigma_{\max }=\frac{M_{\max }}{W_{z}}=\frac{F l}{\frac{\pi D^{3}\left(1-\alpha^{4}\right)}{32}} \\
\tau_{\max }=\frac{2 Q_{\max }}{A}=\frac{2 F}{\pi D^{2}\left(1-\alpha^{2}\right)}
\end{gathered}
$$

$\alpha$ stands for the ratio of anti-swing arm of inner and outer diameter;

$D$ stands for the anti-swing arm of outer diameter;

$l$ stands for the length of the anti-swing arm;

$W_{z}$ stands for the bending section modulus.

$$
\frac{\sigma_{\max }}{\tau_{\max }}=\frac{\frac{F l}{\pi D^{3}\left(1-\alpha^{4}\right)}}{\frac{32}{\pi D^{2}\left(1-\alpha^{2}\right)}}=\frac{16 l}{D\left(1+\alpha^{2}\right)}
$$

According to the formula, if is much larger than D, we can only consider bending normal stress.

According to the formula 3, bending normal stress of anti-swing arm is less than Allowable stress of Q235, Formula is as follows:

$$
\sigma_{\max } \cdot K \leq[\sigma]
$$

$\mathrm{K}$ stands for the safety factor, $\mathrm{K}=1.2$.

Through calculation, anti-swing arm of outer diameter is $40 \mathrm{~mm}$, anti-swing arm of inner diameter is $34 \mathrm{~mm}$.

The stress and strain of anti-swing arm need to be analyzed, we can get the displacement and the stiffness equation $[9,10]$ :

$$
\left\{\begin{array}{l}
\{f\}=[N]\{\delta\}_{e} \\
\{\varepsilon\}=[B]\{\delta\}_{e}
\end{array}\right.
$$

$\{f\}$ stands for force vector in the unit;

$\{\delta\}_{e}$ stands for displacement vector in the unit;

$[N]$ stands for deformation function matrix;

$\{\varepsilon\}$ stands for stain vector in the unit;

$[B]$ stands for strain matrix.

According to the constitutive equation,we can get the stress expression with the strain expression:

$$
\{\sigma\}=[D][B]\{\delta\}_{e}
$$

$\{\sigma\}$ stands for stress vector in the unit;

$[D]$ stands for elastic matrix related to the material.

According to the variational principle,wen can get balance equation, the equation shows the relationship between the nodal force and its displacement:

$$
\{F\}_{e}=[k]_{e}\{\delta\}_{e}
$$

$$
[k]_{e}=\iiint[B]^{T}[D][B] d x d y d z
$$

By ANSYS simulation analysis, as shown in the figure below:
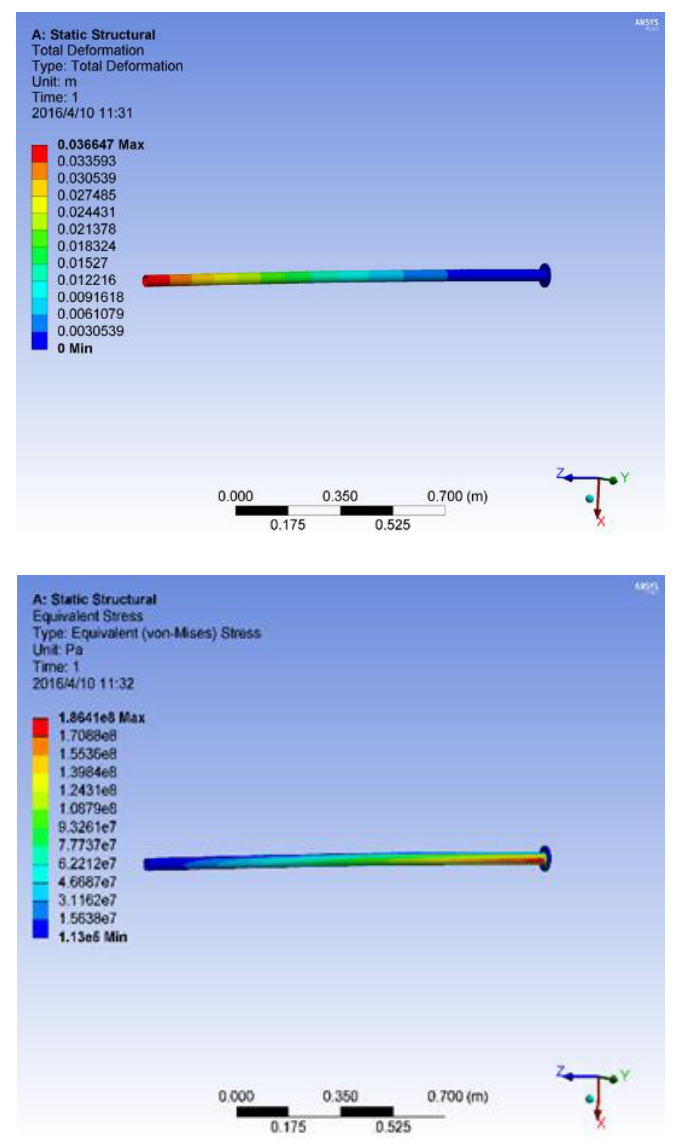

Figure 3. ANSYS simulation of anti-swing arm 
According to Fig. 3, anti-swing arm's biggest variable is $3.6 \mathrm{~cm}$, the maximum stress is $186.4 \mathrm{Mpa}$, satisfying the requirements of Q235.

\subsection{Condition 1: Crane lifting or falling}

When the crane is lifting and falling stage, traction rope of hanging disc must be state of tension, the velocity is calculated as follows:

$$
\begin{gathered}
\cos \angle A D E=\frac{L_{A D}{ }^{2}+L_{D E}{ }^{2}-L_{A E}{ }^{2}}{2 * L_{D E} * L_{A D}} \\
L_{B E}=\sqrt{{L_{A B}{ }^{2}+{L_{A E}}^{2}}^{2}} \\
L_{B E}(\mathrm{t})=\sqrt{L_{A B}{ }^{2}+2 * L_{A D} * L_{D E}(\mathrm{t}) \cos \angle A D E-L_{A D}{ }^{2}-L_{D E}(\mathrm{t})^{2}}
\end{gathered}
$$

\subsection{Condition 2: Crane change-angle}

When the crane is changing the angle, the velocity of traction rope of hanging disc is calculated as follows:

$$
\begin{gathered}
\cos (90-\xi \cdot \mathrm{t}-\varphi)=\frac{L_{A D}{ }^{2}+{L_{D E}}^{2}-L_{A E}{ }^{2}}{2 * L_{D E} * L_{A D}} \\
L_{B E}=\sqrt{{L_{A B}{ }^{2}+L_{A E}{ }^{2}}^{2}} \\
L_{B E}(\mathrm{t})=\sqrt{L_{A B}{ }^{2}+2 * L_{A D} * L_{D E}(\mathrm{t}) \cos (90-\xi \cdot \mathrm{t}-\varphi)-L_{A D}{ }^{2}-L_{D E}(\mathrm{t})^{2}}
\end{gathered}
$$

Derivation for the time variable, we can draw down raction rope of hanging disc's speed stage of function. Traction rope of hanging disc is connected with oiling block, so we need to convert it into angular velocity:

$$
\omega=\frac{\dot{L_{B E}}(\mathrm{t})}{R}
$$

As a result, the output of the motor frequency as follows:

$$
\frac{L_{B E}(\dot{\mathrm{t}}) * 30}{R * \pi} H z
$$

According to the formula, through matlab simulation analysis, this article obtains motor output frequency under different working condition.

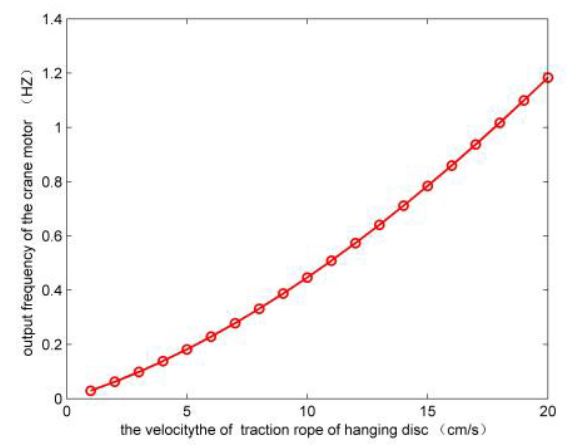

Figure 4. Motor output frequency of condition 1
The Fig. 4 shows that when the crane is lifting and falling stage, The motor output frequency approximation output direct ratio, The maximum output frequency motor is $1.1839 \mathrm{HZ}$, the minimum output frequency is $0.0293 \mathrm{HZ}$. At the same time, pressing the Anti-rolling button, the both sides of crane motor tighten at the same time to reduce the degree of swing.

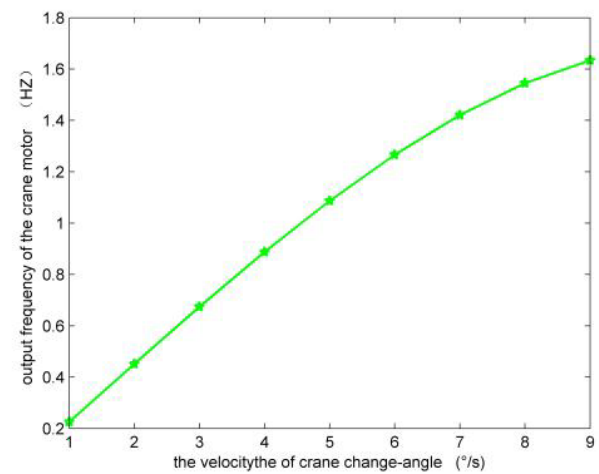

Figure 5. motor output frequency of Condition 2

The Fig. 5 shows that when the crane is changing the angle, the maximum output frequency motor is $1.6342 \mathrm{HZ}$, the minimum output frequency is $0.2255 \mathrm{HZ}$. At the same time, pressing the Anti-rolling button, the both sides of crane motor tighten at the same time to reduce the degree of swing.

\section{Model test of hanging disc mechanical anti-sway device}

According to the crane test, Experimental platform construction are all designed for no damage, not to damage the structure and function of existing equipment, test bench is shown in Fig. 6:

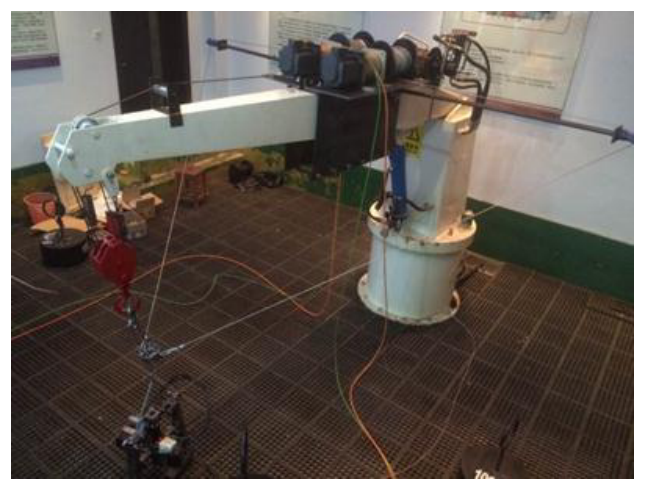

Figure 6. Experimental platform

Test rolling experiment steps:

1 Through PC corresponding control program, object is $100 \mathrm{~kg}$, Rotary speed of crane without hanging disc mechanical anti-sway device is rotating, ship rocking' $s$ angle of the shaking is $4^{\circ}$, Pendulum length is $1.5 \mathrm{~mm}$.

2 Through PC corresponding control program, object is $100 \mathrm{~kg}$, Rotary speed of crane with hanging disc mechanical anti-sway device is rotating, ship rocking' $\mathrm{s}$ angle of the shaking is $4^{\circ}$. Anti-swing arm length is 1.5 $\mathrm{m}$, traction rope of hanging disc length is $0.97 \mathrm{~m}$. 
By installing hanging disc mechanical anti-sway device, Hanging objects track is shown in Fig. 7.

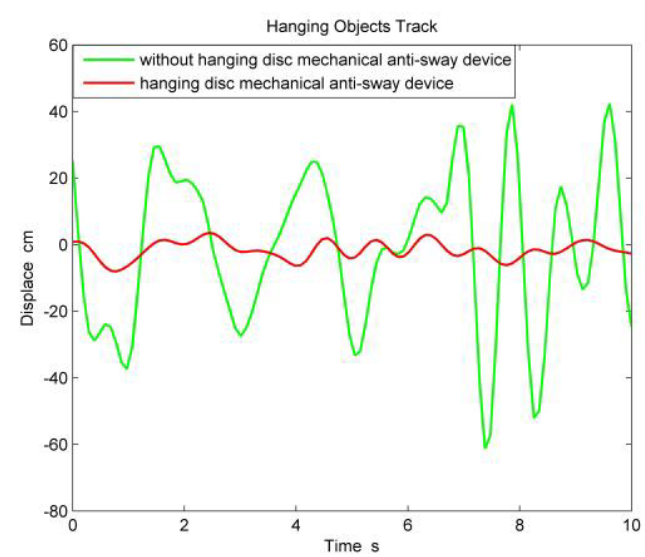

Figure 7. Hanging objects track

\section{Conclusion}

This paper establishes a mathematical model by the different conditions and shows simulation results of constant tension motor output frequency in order to the traction rope of hanging disc must be state of tension; hanging disc anti-sway device can effectively prevent the shake hanging objects, reducing the average swing around $60 \mathrm{~cm}$.

\section{Acknowledgement}

This paper is sponsored by the Fundamental Research Funds for the Central Universities (3132014332, 3132015025) and Natural Science Foundation of Liaoning Province (2015020132).

\section{References}

1. Kimiaghalam B, Homaifar A, Sayrrodsari B. An Applicaton of Model Predictive Control for a Shipboard Crane[C]// Proceedings of the 2001 American Control Conference. (2001)
2. Wen B, Homaifar A, Bikdash M, et al. Modeling and Optimal Control Design of Shipboard Crane[C]//Proceedings of the 1999 American Control Conference. (1999)

3. Robinett, R. D., Groom, K. N., Feddema, J. T., et al. Control System and Method for Payload Control in Mobile Platform Cranes: United States, US 6,496,765[P].2002-12-17.

4. Kimiaghalam B, Homaifar A, Sayrrodsari B. An applicaton of model predictive control for a shipboard crane[C]. Proceedings of the 2001 American Control Conference, Arlington, USA, June, 929-934, (2001)

5. Wang Sheng-hai1, YU Guang-chao, ZHANG Zhijiang, CHEN Hai-quan, SUN Yu-qing. Design Research of an Anti-sway Test Bed for Rotary Crane [J]. Ship Engineering, S1:113-116, (2015)

6. Parker G, Graziano M, Leban F, et al. Reducing Crane Payload Swing Using A Rider Block Tagline Control System[J]. OCEANSE, Aberdeen, June, 1-5, (2007)

7. Robinett, R. D., Groom, K. N., Feddema, J. T., \& Parker, G. G.. Control system and method for payload control in mobile platform cranes[P]. United States Patent. No. US 6,496,765, December 17, (2002)

8. Jang Jae Hoon, Kwon Sung-Ha, Jeung Eun Tae. Pendulation reduction on ship -mounted container crane via T-S fuzzy model[J]. J. Cent. South Univ., 19:163-167, (2012)

9. R. M. T. Raja Ismail, Q. P. HaTrajectory. Tracking and Anti-sway Control of Three-dimensional Offshore Boom Cranes Using Second-order Sliding Modes[C]. IEEE International Conference on Automation Science and Engineering (CASE), Madison, WI, 17-20 Aug, 2013:996-1001.

10. Yongchun Fang, Pengcheng Wang, Ning Sun, et al. Dynamics Analysis and Nonlinear Control of an Offshore Boom Crane[J]. IEEE Transactions on Industrial Electronics, 61(1):414-427, (2014) 